\title{
A HYBRID MULTIPLE CRITERIA DECISION-MAKING MODEL FOR INVESTMENT DECISION MAKING
}

\author{
Li-Chang Hsu \\ Department of Finance, College of Finance and Economics, Ling Tung University, 1 Ling \\ Tung Road, Nantun, Taichung, 40852, Taiwan, R.O.C. \\ E-mail:ltctht87@mail.ltu.edu.tw
}

Received 05 May 2012; accepted 16 August 2012

\begin{abstract}
Investments are accompanied by risks. How investors choose the right investment tools to assist in the selection of investment targets is a topic worth exploring. Therefore, this study aimed to develop an investment decision-making process to deal with this issue. Firstly, we proposed a globalized modified grey relational analysis to select the representative indicators including the financial indicators and risk measurement indicators. Then we combined financial and risk evaluation indicators, and divided companies into low, moderate and high-risk groups through the grey clustering analysis. Finally, Vlse Kriterijumska Optimizacija Kompromisno Resenje (VIKOR) combined with the grey entropy weighting method was applied to business performance evaluation and sorting of each grouping. In order to verify this study, a combination of 21 financial ratios and four risk indicators was utilized in order to verify the evaluation and decision-making process in the operating performance of 62 listed opto-electronics companies in Taiwan. The results of ranking the operating performance for each group can be made available to company managers as a reference in order to enhance competitiveness and business performance. The results can also be used as the basis for decision-making to aid investors who are facing many investment portfolios.
\end{abstract}

Keywords: decision-making process, performance evaluation, VIKOR, grey relational analysis, grey clustering analysis, grey entropy weighting method.

Reference to this paper should be made as follows: Hsu, L.-C. 2014. A hybrid multiple criteria decision-making model for investment decision making, Journal of Business Economics and Management 15(3): 509-529.

JEL Classification: C44, D81, G11, L25.

\section{Introduction}

Good or poor business performance not only depends on whether a company's resources are used effectively and the quality of management ability, but also the company's ability to show the potential for growth and development in the future. This allows investors to fully understand the company's business situation, financial performance and risks, which could be used as important references when making investment decisions. 
A literature review of operating performance evaluation shows most past studies have mostly concentrated on the financial performance of companies (Wang 2009). Among the different types of analysis, ratio analysis is the most commonly used analysis for evaluating a company's financial performance. Therefore, using financial ratios to measure the financial position and operating performance of an enterprise has always been a very effective evaluation method.

However, the disadvantages of the financial ratios are that the company cannot be displayed within a given period. If the worst situation occurs in the market, the company can withstand the maximum possible risk of loss. Therefore, this study is based on the concept of risk management. We take business risk measures into account in performance evaluation. In this way, we can develop a comprehensive evaluation of a company's financial performance and risk characteristics.

Investors often have insufficient information and lack of expertise to make investment decisions, leading to erroneous investing judgments. Therefore, how to use limited information to accurately make decision is the most difficult issue for investors. Following this logic, we apply grey theory including grey relational analysis (GRA) and grey clustering analysis (GCA), which fitted to study investment decision-making problems with poor information. This study uses GRA to examine the financial and risk factors, which are closely related to the operational performance, and then selects the appropriate indicators for the performance evaluation. We use GCA, a classification method, to judge the decision-making object based on selected indicators. According to the results of cluster classification, investors can precisely invest the objects.

In actual evaluation, evaluation criteria are often conflicting, making it difficult to find a solution that meets all the criteria. Through the multiple criteria decision making (MCDM) method, conflict between the evaluation criteria can generate a compromise solution, which can assist the decision-maker in decision-making. According to Wang (2009), financial performance evaluation is a MCDM problem. Therefore, this study uses the MCDM method VIKOR combined (Opricovic, Tzeng 2007) with the grey entropy weight method (You, Wen 2005), proposed a VIKOR-E method for each grouping of financial and risk indicators to conduct comprehensive evaluation and ranking, respectively.

In order to verify the feasibility of the investment decision-making process mentioned above, this study uses the listed opto-electronics companies in Taiwan as an example, as an assessment of business performance. The conclusions can provide managers with a basis for integration or mergers in the future and can also serve as a reference for investors when selecting investment targets.

\section{Literature review}

\subsection{The application of GRA}

GRA is based on the degree of the similarity of developing a trend among factors to measure how close two sequences are. It has been widely applied in various fields, for 
example, to deal with decision-making problems. Golmohammadi and Mellat-Parast (2012) developed a decision-making model based on the grey relational analysis for supplier selection. Pramanik and Mukhopadhyaya (2011) developed an intuitionistic fuzzy multi criteria group making method with GRA for teacher selection in higher education. Zavadskas et al. (2009) proposed a complex proportional assessment (COPRAS) with grey relational model (COPRAS-G) to assessment of alternatives.

It can also be used to select representative indicators, such as in the study by Feng and Wang (2000) who used GRA to divide 63 evaluation indicators into three categories: production, marketing, and execution. Based on the degree of the relationship between an indicator and the other indicators in the same category, a representative indicator is selected from each category. Wang (2009) applies GRA to partition financial ratios into several groups, and find representative indices from the groups. In view of the above facts, this study focuses on the use of GRA to select the representative financial indicators for listed companies in the high-tech industry.

\subsection{The application of GCA}

GCA is one of the clustering algorithms proposed by Deng (1987). Its purpose is to investigate how data are collected for processing and classification. According to a set of classification indicators, data can be classified into several different sub-categories, and the data within the same cluster have the same characteristics, while the data in each cluster may have different characteristics. The results of GCA can very easily show the underlying structures and clusters between data, and this information helps to further the effective handling and use of the data for different characteristics.

GCA is widely used in many applications. For example, Hsu (2011) adopted GCA for classifying policyholder risk attitudes. Liu et al. (2012) used GCA to deal with overseas project loan decision-making. Zhang et al. (2011) adopted GCA to fulfill the evaluation targets for the functional requirements of a system. In these applications, GCA has proven very useful for classifying data, especially in cases with limited messages and no rules available for data processing.

\subsection{The application of the VIKOR method}

MCDM is one of the most important parts of decision theory. It has been extended to relevant decision-making and evaluation methods. In the MCDM model, TOPSIS and VIKOR are used to rank alternatives according to the concept of the compromise solution to solve the competing problem between the evaluation criteria. Olson (2004) mentioned that it is not appropriate to use the m-dimensional Euclidean distance to calculate the separation measures. Shih et al. (2007) mentioned that when there are different methods of data standardization, TOPSIS results in significant impact on the final selection results.

Therefore, VIKOR has been proposed for correcting the disadvantages of TOPSIS (Opricovic 1998). Since VIKOR has been widely used in various fields, such as in the 
study by Ilangkumaran and Kumanan (2012) proposed a method combining the fuzzy analytic hierarchy process (FAHP) and VIKOR to select an optimum strategy for a textile industry. Wu et al. (2012) proposed a method combining AHP and VIKOR for university performance evaluation. Therefore, this study used the VIKOR method to solve the MCDM problem.

However, Hallerbach and Spronk (2002) mentioned that when facing financial problems, we could use MCDM technology to solve financial decision-making problems. Wang (2009) also mentioned that financial performance evaluation is a MCDM problem. Yalçin et al. (2012) applied MCDM tools to evaluate the financial performance of the Turkish manufacturing industry. From the above, one can easily conclude that MCDM can be used to evaluate financial performance. Therefore, this study combines financial and risk indicators, and the application of the MCDM method (VIKOR) combined with the entropy weighting method to evaluate the operating performance of high-tech companies.

\section{Research methodology}

\subsection{Modified grey relational analysis}

GRA can be divided into two categories: localized and globalized GRA models. This study is based on Wang's suggestion (Wang 2009) that globalized GRA be used to select the performance evaluation indicators. However, GRA in calculating the grey relational coefficient has some shortcomings. To solve this shortage of the traditional GRA, this study proposes an MGRA. We proposed a globalized modified GRA, namely the globalized MGRA, as described below.

Using GRA, the property description of a sequence should be in the same direction. Furthermore, in order to make the sequences satisfy the comparability, we have to do data processing. There are three ways to dispose primary data, larger-the-better, smaller-the-better and nominal-the-better. If $m$ alternatives and $n$ attributes exist, the $i$-th alternative can be expressed as $X_{i}=\left(x_{i 1}, x_{\mathrm{i} 2}, \ldots, x_{i n}\right)$, where $x_{i j}$ is the performance value of attribute $j$ of alternative $i$. Then the sequence after the data preprocessing $X_{i j}^{*}$ can be calculated as follows:

1. Larger-the-better - upper-bound effectiveness:

$$
X_{i j}^{*}=\frac{x_{i j}-\min _{i} x_{i j}}{\max _{i} x_{i j}-\min _{i} x_{i j}}
$$

2. Smaller-the-better - lower-bound effectiveness:

$$
X_{i j}^{*}=\frac{\max _{i} x_{i j}-x_{i j}}{\max _{i} x_{i j}-\min _{i} x_{i j}} ;
$$

3. Nominal-the-better - moderate effectiveness: 


$$
X_{i j}^{*}=\frac{\left|x_{i j}-x_{o b j}\right|}{\max _{i} x_{i j}-x_{o b j}}
$$

where $i=1,2, \ldots, m, j \in i, \max x_{i j}$ is the maximum value of $x_{j}$, min $x_{i j}$ is the minimum value of $x_{j}$, max $x_{i j} \geq x_{i j} \geq \min x_{i j}$.

The main steps of globalized MGRA are described below.

Step 1: Calculate the grey relational coefficient.

The grey relational coefficient is calculated from the normalized data sequences' $X_{i j}^{*}$. It is used for determining the distance between $x_{j}(k)$ and $x_{i}(k)$, and can be defined as:

$$
\gamma\left(x_{i}(k), x_{j}(k)\right)=\frac{\Delta_{\min }+\varsigma \Delta_{\max }}{\Delta_{i j}(k)+\varsigma \Delta_{\max }}
$$

where $\gamma\left(x_{i}(k), x_{j}(k)\right)$ is the grey relational coefficient between $x_{i}(k)$ and $x_{j}(k)$, and $\Delta_{i j}(k)=\left|x_{i}(k)-x_{j}(k)\right|, k=1,2, \ldots, n, i=1,2, \ldots, m, j \in i$.

$\Delta_{\text {max }}=\max _{\forall j \in i} \max _{\forall k}\left|x_{i}(k)-x_{j}(k)\right|, \Delta_{\min }=\min _{\forall j \in i} \min _{\forall k}\left|x_{i}(k)-x_{j}(k)\right|, \mathrm{V}$ is the distinguishing coefficient, and $\varsigma \in[0,1]$ is usually assigned the value of 0.5 .

In order to improve the shortcoming of traditional grey relational coefficient, we apply a distance term to expand the relationship between evaluation object and the optimal evaluation object, and adjust the distance by the adjustment coefficient. Therefore, we proposed a modified grey relational coefficient as follows.

$$
\gamma^{\prime}\left(x_{i}(k), x_{j}(k)\right)=\eta\left(\frac{\Delta_{\min }+\varsigma \Delta_{\max }}{\Delta_{i j}(k)+\varsigma \Delta_{\max }}\right)+(1-\eta)\left(1-\frac{\Delta_{i j}(k)}{\Delta_{\max }}\right)
$$

where $1-\frac{\Delta_{i j}(k)}{\Delta_{\max }}$ is the distance term, $\eta$ is the adjustment coefficient, $\eta \in[0,1]$. In this study, the adjustment coefficient $\eta$ was set as 0.5 .

Step 2: Constructing the grey relational matrix.

Supposing there are $m$ reference sequences and $n$ comparative sequences, the grey relational matrix $R$ can be described as follows:

$$
R_{m \times m}=\left[\begin{array}{cccc}
\Gamma_{11} & \Gamma_{12} & \cdots & \Gamma_{1 m} \\
\Gamma_{21} & \Gamma_{22} & \cdots & \Gamma_{2 m} \\
\vdots & \vdots & \ddots & \vdots \\
\Gamma_{m 1} & \Gamma_{m 2} & \cdots & \Gamma_{m m}
\end{array}\right],
$$

where $\mathrm{G}_{i j}$ is the grey relational grade between $x_{i}$ and $x_{j}$. The grey relational grade is obtained from the mean of grey relational coefficient, that is $\Gamma_{i j}=\Gamma\left(x_{i}, x_{j}\right)=\frac{1}{n} \sum_{k=1}^{n} \gamma^{\prime}\left(x_{i}(k), x_{j}(k)\right)$. 


\subsection{Grey clustering analysis}

The steps of GCA are as follows:

Step 1: Construct a grey number evaluation matrix $D$.

Suppose that there exist $n$ decision-making objects, $m$ decision-making indicators, $s$ different grey classes, and according to sample value $d_{i j}(i=1,2, \ldots, n ; j=1,2, \ldots, \mathrm{m})$, we can categorize indicator $j$ into grey class $k(k=1,2, \ldots, s)$, and call it grey clustering. From above, we construct the grey number evaluation matrix $D=\left[d_{i j}\right]$,

$$
D=\left[\begin{array}{cccc}
d_{11} & d_{12} & \cdots & d_{1 m} \\
d_{21} & d_{22} & \cdots & d_{2 m} \\
\vdots & \vdots & & \vdots \\
d_{n 1} & d_{n 2} & \cdots & d_{n m}
\end{array}\right] .
$$

Step 2: Set the whitenization weight function.

In this study, the triangle whitenization weight function is established. Given $f_{j k}$, which is the whitenization weight functions of the $j$-th indicator, build the whitenization weight functions $f_{j k}$ for three grey classes, as follows:

1. $f_{j 1}(x)=\left\{\begin{array}{cl}1, & x \in\left[0, \lambda_{j 1}(2)\right) \\ 1-\frac{x-\lambda_{j 1}(2)}{\lambda_{j 1}(3)-\lambda_{j 1}(2)}, & x \in\left[\lambda_{j 1}(2), \lambda_{j 1}(3)\right) \\ 0, & x \in\left[\lambda_{j 1}(3), \infty\right)\end{array}\right.$

2. $f_{j 2}(x)=\left\{\begin{array}{cc}\frac{x-\lambda_{j 2}(1)}{\lambda_{j 2}(2)-\lambda_{j 2}(1)}, & x \in\left[\lambda_{j 2}(1), \lambda_{j 2}(2)\right) \\ 1-\frac{x-\lambda_{j 2}(2)}{\lambda_{j 2}(3)-\lambda_{j 2}(2)}, & x \in\left[\lambda_{j 2}(2), \lambda_{j 2}(3)\right) \\ 0 & x \in\left[0, \lambda_{j 2}(1)\right), x \in\left[\lambda_{j 2}(3), \infty\right)\end{array}\right.$

3. $f_{j 3}(x)=\left\{\begin{array}{cl}0, & x \in\left[0, \lambda_{j 3}(1)\right) \\ \frac{x-\lambda_{j 3}(1)}{\lambda_{j 3}(2)-\lambda_{j 3}(1)}, & x \in\left[\lambda_{j 3}(1), \lambda_{j 3}(2)\right) . \\ 1, & x \in\left[\lambda_{j 3}(2), \infty\right)\end{array}\right.$

Step 3: Obtain the cluster weight matrix $\eta_{j k}$. 
From the whitenization weight function $f_{j k}$, cluster weight matrix $\eta_{j k}$ can be obtained by

$$
\eta_{j k}=\lambda_{j k} / \sum_{j=1}^{m} \lambda_{j k}, \quad k=1,2, \cdots, s,
$$

Step 4: Obtain the cluster coefficient matrix $\sigma_{i k}$.

Calculate the cluster coefficient $\sigma_{i k}$ for the object $i$ belonging to the $k$-th grey class, then

$$
\sigma_{i k}=\sum_{j=1}^{m} f_{j k}\left(d_{i j}\right) \eta_{j k}, \quad i=1,2, \cdots, n, \quad k=1,2, \cdots, s .
$$

Step 5: Construct the cluster vector $\sigma_{i}$ and evaluate.

Supposing that $\sigma_{i}$ is the cluster vectors, then $\sigma_{i}=\left(\sigma_{i 1}, \sigma_{i 2}, \ldots, \sigma_{i k}\right), i=1,2, \ldots, n$. Taking the maximum value of $\left(\sigma_{i 1}, \sigma_{i 2}, \ldots, \sigma_{i k}\right)$, confirm which grey class the clustering belongs to, i.e. $\sigma_{i k^{*}}=\max _{1 \leq k \leq s}\left\{\sigma_{i k}\right\}$. Then we can conclude that object $i$ belongs to grey class $k^{*}$.

\subsection{Grey entropy weight method}

The grey entropy weight method is used to determine the attribute weights by the evaluation matrix, which is an objective weighting method (Han, Liu 2011). Recently, entropy weight method was used in GRA. The main steps of the grey entropy weight method are as follows (You, Wen 2005):

Step 1: Construct the original matrix $B$ with $n$ evaluation criteria and the $m$ evaluation alternative is shown as follows:

$$
B=\left[\begin{array}{cccc}
x_{11} & x_{12} & \cdots & x_{1 n} \\
x_{21} & x_{22} & \cdots & x_{2 n} \\
\vdots & \vdots & \ddots & \vdots \\
x_{n 1} & x_{n 2} & \cdots & x_{m n}
\end{array}\right]_{m \times n},
$$

where $x_{i j}(i=1,2, \ldots, m, j=1,2, \ldots, n)$ is the performance value of evaluation criteria $j$ of alternative $i$.

Step 2: Construct normalized matrix $R$ :

where $\gamma_{i j}=x_{i j} / \sqrt{\sum_{i=1}^{m} x_{i j}^{2}}$.

$$
R=\left[\gamma_{i j}\right]
$$

Step 3: Calculate the grey entropy value $e_{j}$ of the evaluation criteria $j$ :

$$
e_{j}=\frac{1}{0.6487 \times m} \sum_{i=1}^{m} W_{e}\left(\gamma_{i j} / B_{j}\right),
$$

where $W_{e}=x e^{(1-x)}+(1-x) e^{x}-1$. 
Step 4: Calculate the criteria weight $w_{j}$ :

where $E=\sum_{j=1}^{n} e_{j}$.

$$
w_{j}=\left[\left(1-e_{j}\right) /(n-E)\right] / \sum_{j=1}^{n}\left[\left(1-e_{j}\right) /(n-E)\right],
$$

\subsection{VIKOR-E method}

We propose a method combining the VIKOR method (Liu, Wang 2011; Opricovic, Tzeng 2007) with the grey entropy weight method (VIKOR-E method) to solve the MCDM problem. The main steps of the VIKOR-E method are as follows:

Step 1: Determine the positive ideal solution $\left(f^{*}\right)$ and negative ideal solution $\left(f^{-}\right)$:

$$
\begin{aligned}
& f_{i}^{*}=\left\{\left(\max _{k} f_{i k} \mid k \in I_{1}\right),\left(\min _{k} f_{i k} \mid k \in I_{2}\right) \mid \forall k=1,2, \cdots, m\right\}, \\
& f_{i}^{-}=\left\{\left(\min _{k} f_{i k} \mid k \in I_{1}\right),\left(\max _{k} f_{i k} \mid k \in I_{2}\right) \mid \forall k=1,2, \cdots, m\right\},
\end{aligned}
$$

where $k(k=1,2, \ldots, m)$ is the evaluation alternative and $i(i=1,2, \ldots, n)$ is the evaluation criteria. $f_{i k}$ is a performance evaluation value of the $i$-th criterion for the $k$-th alternative. $I_{1}$ is the cluster of benefit-oriented criteria. $I_{2}$ is the cluster of cost-oriented criteria.

Step 2: Determine the weights of criteria.

This study applied the grey entropy weight method to calculate the weights for each criterion (see section 2.3).

Step 3: Calculate the ideal value $S_{k}$ and negative value $R_{k}$ :

$$
\begin{gathered}
S_{k}=\sum_{i=1}^{n} w_{i}\left(f_{i}^{*}-f_{i k}\right) /\left(f_{i}^{*}-f_{i}^{-}\right), \\
R_{k}=\max _{i}\left[w_{i}\left(f_{i}^{*}-f_{i k}\right) /\left(f_{i}^{*}-f_{i}^{-}\right)\right],
\end{gathered}
$$

where $k=1,2, \ldots, m, w_{i}$ are the weights of criteria that were obtained by the grey entropy weight method in section 2.3.

Step 4: Calculate the VIKOR values $Q_{k}$.

The $Q_{k}$ are defined as:

$$
Q_{k}=v\left[\frac{S_{k}-S^{*}}{S^{-}-S^{*}}\right]+(1-v)\left[\frac{R_{k}-R^{*}}{R^{-}-R^{*}}\right],
$$

where $S^{*}=\min _{k} S_{k}, S^{-}=\max _{k} S_{k}, R^{*}=\min _{k} R_{k}, R^{-}=\max _{k} R_{k}, v$ is the weight of the decision-making strategy. When $v>0.5$, the value of $Q_{k}$ will tend toward majority agreement. When $v<0.5$, the value of $Q_{k}$ will indicate majority negative attitude. In general, $v=<0.5$ in empirical research (Mohaghar et al. 2012). 
Step 5: According to $S, R$ and $Q$ separately rank the evaluation alternative.

A smaller VIKOR value indicates better multi-response performance. Therefore, the minimum VIKOR value is the best solution. When the following two conditions are met simultaneously, we can rank the objects by $Q_{k}$ values.

Condition 1. Acceptable advantage

$$
Q^{\prime \prime}-Q^{\prime} \geq \frac{1}{N-1},
$$

where $N$ is the number of evaluation alternatives. $Q^{\prime}$ is the $Q$ value of the alternative which should be sorted first based on the sorting by $Q_{k}$ in decreasing order. $Q^{\prime \prime}$ is the $Q$ value of the alternative by which to sort the second. If two or more evaluation alternatives exist, we must order sort first, second, third, etc., the relationship between the alternative meets the above equation.

Condition 2. Acceptable decision reliability

With the $Q$ value after descending order, the $S$ value (or $R$ value) of the first sorting alternatives must also be at the same time which is larger than the $S$ value (or $R$ value) of the second sorting alternative. If the existence of two or more evaluation alternatives, we must order sort first, second, third, etc., the relationship between the alternative meets the condition 2 .

If sorting the first and second alternatives meets the condition 1 and condition 2 at the same time, it means the first sorting alternative is significantly better than the second. Accept the object sorted first as the best alternative. If sorting the first and second alternatives meets condition 2 only and does not meet condition 1, then there is no significant difference between sorting first and second alternatives. In this case, the two alternatives can be given the same rank grade. If sorting the first and other alternatives only meets condition 2 and does not meet condition 1, there is no significant difference between these alternatives. Thus, acceptance of these alternatives can be given the same rank grade simultaneously.

\section{Variable description}

\subsection{Indicators of financial performance}

We follow previous studies (Halkos, Tzeremes 2012; Stankevičienè, Mencaitė 2012) and use various financial ratios to measure financial performance. The 21 most commonly used financial ratios were selected for this study. These ratios were grouped into three categories, including operating ability, solvency and profitability, as depicted in Table 1 . 
Table 1. The financial indicators on three categories

\begin{tabular}{|c|c|}
\hline Category & Financial ratios \\
\hline Operating ability & $\begin{array}{l}\text { Total assets turnover ratio }(\mathrm{O} 1) \text {, Accounts receivable turnover }(\mathrm{O} 2), \\
\text { Inventory turnover }(\mathrm{O} 3) \text {, Fixed assets turnover }(\mathrm{O} 4) \text {, Turnover of } \\
\text { networth }(\mathrm{O} 5) \text {, Days-A/R turnover }(\mathrm{O} 6) \text {, Days-inventory turnover }(\mathrm{O} 7)\end{array}$ \\
\hline Solvency & $\begin{array}{l}\text { Cash flow adequacy ratio (S1), Cash reinvestment ratio (S2), Current } \\
\text { ratio (S3), Quick ratio (S4), Long-term capital ratio (S5), Times interest } \\
\text { earned (S6), Oper. income/Capital (S7), Pre tax income/Capital (S8) }\end{array}$ \\
\hline Profitability & $\begin{array}{l}\text { Return on assets (P1), Return on equity (P2), Profit margin (P3), } \\
\text { Operating margin (P4), Net profit margin (P5), Earnings per share (P6) }\end{array}$ \\
\hline
\end{tabular}

\subsection{Indicators of risk factors}

From an investor's point of view, the total risk can be divided into systematic risk and non-systemic risk (Alaghi 2012). Systematic risk is due to macroeconomic factors or internal accounting variables which lead to fluctuations in the rate of return. This cannot be reduced by diversification. Non-systematic risk is the risk that the investor can eliminate by diversification. Hamada (1972) and Bowman (1979) have shown that systematic risk in general can be divided into operational (business) risk and financial risk. Operational risk is the risk that is caused by fluctuations of operating income. Financial risk is the risk of a company being unable to pay its interest and lease payments. We use the degree of operating leverage (DOL) and degree of financial leverage (DFL) to estimate a company's operating risk and financial risk, respectively (Alaghi 2012), which are defined as follows:

$$
\mathrm{DOL}=(\text { Net sales }- \text { Variable cost }) / \text { Income from operations, }
$$

$\mathrm{DFL}=$ Income from operations/(Income from operations - Interest expenses).

Greater changes in revenue affect profit volatility. As a result, the greater the DOL, the greater the operational risk. The higher the DFL, the greater the financial risk. For a company with high DOL and high DFL, a crisis has occurred.

In order to reach the quantitative investment decision-making, it is becoming very important for the investor to know how to analyze and quantify the risk. There are several tools that investors can use to help measure asset risk, such as standard deviation, return variance or the beta coefficient in the capital asset pricing model (CAPM). Among them, the level of risk for listed companies in the stock market can be reflected through the beta coefficient, which is defined as $\beta_{i}=\operatorname{cov}\left(R_{i}, R_{m}\right) / \operatorname{Var}\left(R_{m}\right)$. The beta coefficient $\left(\beta_{i}\right)$ for a company can be obtained from CAPM. Its form is:

$$
R_{i}=R_{f}+\beta_{i}\left(R_{m}-R_{f}\right)+\varepsilon
$$

where $\beta_{i}$ is the beta value for the stock $i, R_{i}$ is the return on stock $i, R_{f}$ is the risk-free rate of return, $R_{m}$ is the rate of return on the stock market index, $\varepsilon$ is the error term. The higher the beta values for a stock, the greater the market risk. When the beta value is equal to 0 , it indicates that the company's stock is not subject to market risk. 
RAROC is one of the risk measurement variables that take into account the rewards and risks of assets. It was first used by Bankers Trust in the late 1970's and since has been widely used in the operating performance evaluation of banks. The basic definition of RAROC is the ratio of risk adjusted return to economic capital (Prokopczuk et al. 2007). For now, we do not have a standard formula to estimate RAROC. This study follows TEJ's definition, in which RAROC is defined as (Hsu et al. 2012):

$$
\mathrm{RAROC}=(\text { Unrealized gains and losses } / \text { Days }) /(\text { Value at risk } / \mathrm{t}) .
$$

The RAROC value indicates the size of the rewards brought about by the loss of one unit of capital, and effectively measures the efficiency of the risk of earning revenue; therefore, the bigger the value the better.

\section{Empirical results}

\subsection{Sample and data source}

In order to verify the proposed investment decision-making process, we applied listed opto-electronics companies in Taiwan as a research case. After deleting companies with incomplete information and data, a total of 62 listed companies were selected as evaluation alternatives. The listed company's annual report and financial statements for 2010 were used as the primary source of data for analysis. The annual data of 21 financial indicators, DOL, DFL and the beta coefficient were taken from the Taiwan Economic Journal (TEJ) Data Bank. The RAROC values were obtained from the VaR system v2.1 of TEJ.

\subsection{The results of GRA for selecting representative indicators}

Based on Feng and Wang (2000), this study uses globalized MGRA by clustering to select representative financial indicators. The globalized MGRA requires data to satisfy comparability. This study using grey relational generation to conduct data processing (Eqs. (1)-(3)). Among the 21 financial ratio indicators, the indicators O6 (days-A/R turnover) and $\mathrm{O} 7$ (days-inventory turnover) are regarded as the smaller the better, and the remaining indicators are regarded as the larger the better. We take the distinguishing and adjustment coefficient of 0.5 . With the normalized values substituted into the Eq. (5) and (6), we can obtain the grey relational matrices of group to analyze operating ability, solvency and profitability, respectively, as shown in Table 2. The numbers in Table 2 show the grey relational grade between any two indicators.

Feng and Wang (2000) proposed clustering to select representative indicators for analysis. According to their suggestion, we also take 0.7 as the threshold value. In Table 2, the solvency of the grey relational matrix shows that S3 and S7 are divided into the same group because they both have the same score (the entire grey relational grade is higher than 0.7 ), but $0.7995>0.7991$, so the indicator S3 is selected as the representative indicator for the group. The results of the remaining selection of representative indicators 
are shown in Table 3 . Table 3 shows that among the 21 financial ratios, we selected 12 evaluation indicators to evaluate the financial performance of Taiwan's listed optoelectronics companies. Namely, the total assets turnover ratio (O1), inventory turnover (O3), turnover of net worth (O5), days-A/R turnover (O6), cash reinvestment ratio (S2), current ratio (S3), quick ratio (S4), long-term capital ratio (S5), pre tax income/capital (S8), operating margin (P4), net profit margin (P5) and earnings per share (P6).

We obtain the grey relational matrices (calculated by Eqs. (1)-(6)) to analyze risk measurement, as shown in Table 2. Table 2 shows that we selected two risk measurement indicators from the four risk indicators; namely, DOL and beta coefficient, respectively.

Table 2. The results of the grey relational matrix

\begin{tabular}{|c|c|c|c|c|c|c|c|c|}
\hline \multicolumn{9}{|c|}{ Operating ability } \\
\hline & O1 & $\mathrm{O} 2$ & $\mathrm{O} 3$ & $\mathrm{O} 4$ & $\mathrm{O} 5$ & O6 & O7 & \\
\hline $\mathrm{O} 1$ & 1.0000 & 0.7732 & 0.6646 & 0.6751 & 0.8626 & 0.5982 & 0.5992 & \\
\hline $\mathrm{O} 2$ & 0.7687 & 1.0000 & 0.7534 & 0.7482 & 0.8196 & 0.5284 & 0.5308 & \\
\hline $\mathrm{O} 3$ & 0.6577 & 0.7530 & 1.0000 & 0.9446 & 0.7347 & 0.3907 & 0.4102 & \\
\hline $\mathrm{O} 4$ & 0.6684 & 0.7478 & 0.9446 & 1.0000 & 0.7464 & 0.3782 & 0.4008 & \\
\hline O5 & 0.8599 & 0.8197 & 0.7354 & 0.7470 & 1.0000 & 0.5298 & 0.5267 & \\
\hline O6 & 0.5907 & 0.5284 & 0.3915 & 0.3790 & 0.5293 & 1.0000 & 0.7676 & \\
\hline $\mathrm{O} 7$ & 0.5911 & 0.5302 & 0.4102 & 0.4008 & 0.5256 & 0.7673 & 1.0000 & \\
\hline \multicolumn{9}{|c|}{ Solvency } \\
\hline & S1 & S2 & S3 & $\mathrm{S} 4$ & S5 & S6 & S7 & S8 \\
\hline S1 & 1.0000 & 0.6656 & 0.8718 & 0.8817 & 0.9166 & 0.8848 & 0.7677 & 0.6984 \\
\hline S2 & 0.6636 & 1.0000 & 0.7047 & 0.6996 & 0.6154 & 0.6198 & 0.7777 & 0.7882 \\
\hline S3 & 0.8711 & 0.7050 & 1.0000 & 0.9676 & 0.8326 & 0.8270 & 0.7995 & 0.7505 \\
\hline S4 & 0.8811 & 0.6999 & 0.9676 & 1.0000 & 0.8508 & 0.8471 & 0.7875 & 0.7391 \\
\hline S5 & 0.9159 & 0.6149 & 0.8322 & 0.8505 & 1.0000 & 0.9569 & 0.7209 & 0.6530 \\
\hline S6 & 0.8840 & 0.6197 & 0.8268 & 0.8469 & 0.9569 & 1.0000 & 0.7315 & 0.6664 \\
\hline S7 & 0.7659 & 0.7774 & 0.7991 & 0.7870 & 0.7209 & 0.7312 & 1.0000 & 0.8918 \\
\hline S8 & 0.6962 & 0.7880 & 0.7499 & 0.7385 & 0.6530 & 0.6660 & 0.8918 & 1.0000 \\
\hline \multicolumn{9}{|c|}{ Profitability } \\
\hline & & P1 & P2 & P3 & P4 & P5 & P6 & \\
\hline & P1 & 1.0000 & 0.8658 & 0.6572 & 0.7791 & 0.8753 & 0.4763 & \\
\hline & $\mathrm{P} 2$ & 0.8664 & 1.0000 & 0.5815 & 0.7028 & 0.7784 & 0.3882 & \\
\hline & P3 & 0.6221 & 0.5370 & 1.0000 & 0.8065 & 0.7308 & 0.7328 & \\
\hline & P4 & 0.7637 & 0.6810 & 0.8127 & 1.0000 & 0.8351 & 0.6171 & \\
\hline & P5 & 0.8618 & 0.7540 & 0.7308 & 0.8296 & 1.0000 & 0.5669 & \\
\hline & P6 & 0.5589 & 0.4823 & 0.7971 & 0.6989 & 0.6696 & 1.0000 & \\
\hline \multicolumn{9}{|c|}{ Risk measurement } \\
\hline & & & DOL & DFL & Beta & RAROC & & \\
\hline & & DOL & 1.0000 & 0.9507 & 0.4951 & 0.9010 & & \\
\hline & & DFL & 0.9481 & 1.0000 & 0.4992 & 0.8944 & & \\
\hline & & Beta & 0.4650 & 0.4939 & 1.0000 & 0.4368 & & \\
\hline & & RAROC & 0.8946 & 0.8932 & 0.4368 & 1.0000 & & \\
\hline
\end{tabular}


Table 3. The classification of financial ratios and selection of the representative indicators

\begin{tabular}{|c|c|c|c|}
\hline Category & Cluster & $\begin{array}{l}\text { Financial ratios within the } \\
\text { cluster }\end{array}$ & Representative indicator of each group \\
\hline \multirow{4}{*}{$\begin{array}{l}\text { Operating } \\
\text { ability }\end{array}$} & $\mathrm{C} 1$ & $\mathrm{O} 1$ & O1: Total assets turnover ratio \\
\hline & $\mathrm{C} 2$ & $\mathrm{O} 2, \mathrm{O} 5$ & O5: Turnover of net worth \\
\hline & $\mathrm{C} 3$ & $\mathrm{O} 3, \mathrm{O} 4$ & O3: Inventory turnover \\
\hline & $\mathrm{C} 4$ & O6, O7 & O6: Days-A/R turnover \\
\hline \multirow[t]{5}{*}{ Solvency } & $\mathrm{C} 5$ & S1, S5, S6 & S5: Long-term capital ratio \\
\hline & C6 & $\mathrm{S} 2$ & S2: Cash reinvestment ratio \\
\hline & $\mathrm{C} 7$ & S3, S7 & S3: Current ratio \\
\hline & $\mathrm{C} 8$ & S4 & S4: Quick ratio \\
\hline & C9 & S8 & S8: Pre tax income/Capital \\
\hline \multirow[t]{3}{*}{ Profitability } & $\mathrm{C} 10$ & $\mathrm{P} 1, \mathrm{P} 2, \mathrm{P} 3, \mathrm{P} 4$ & P4: Operating margin \\
\hline & $\mathrm{C} 11$ & P5 & P5: Net profit margin \\
\hline & $\mathrm{C} 12$ & P6 & P6: Earnings per share \\
\hline
\end{tabular}

\subsection{Results of grey clustering analysis}

This study used Eqs. (1)-(3) to achieve the standardization of the original data, and then used grey clustering analysis. In practical application, grey clustering analysis operates as follows:

Step 1: This study first makes sure the evaluation alternative $i$ is the 62 listed optoelectronics companies in Taiwan. The evaluation indicator $j$ is 12 financial ratio indicators plus the two risk measurement indicators (DOL and beta coefficient), with a total of 14 evaluation criteria. Among the 14 evaluation criteria, the indicators DOL, beta coefficient, and $\mathrm{O} 6$ have the smaller-the-better characteristic, and the remaining indicators have the larger-the-better characteristic. Therefore, this study used Eqs. (1)-(3) to standardize the original data (normalizing data between 0 and 1) to establish the sample matrix $D$ :

$$
D=\left[\begin{array}{ccc}
0.9074 & \cdots & 0.1774 \\
0.9023 & \cdots & 0.3554 \\
\vdots & \vdots & \vdots \\
0.9029 & \cdots & 0.3962
\end{array}\right]
$$

Step 2: According to whether the risk probability of occurrence is high or low, the 62 listed opto-electronics companies in Taiwan were divided into three categories: low, moderate and high-risk probability groups. A low-risk probability company is one with relatively low risk of future financial crisis. A moderate-risk probability company is one with risk of future financial crisis which is lower than the high-risk companies. A high-risk probability company is one with poor financial position; risk of future financial crisis is relatively large. 
Table 4. The results of grey clustering coefficient and grey classification

\begin{tabular}{|c|c|c|c|c|c|c|c|c|c|}
\hline Company & 1 & 2 & 3 & 4 & 5 & 6 & 7 & 8 & 9 \\
\hline$k=1$ & 0.5960 & 0.4663 & 0.5637 & 0.5142 & 0.1519 & 0.3866 & 0.3733 & 0.4134 & 0.3544 \\
\hline$k=2$ & 0.2760 & 0.3380 & 0.2449 & 0.3447 & 0.463 & 0.3562 & 0.4027 & 0.3556 & 0.4092 \\
\hline$k=3$ & 0.1280 & 0.1957 & 0.1915 & 0.1411 & 0.385 & 0.2572 & 0.2240 & 0.2310 & 0.2364 \\
\hline Risk class & High & Moderate & High & High & Moderate & High & Moderate & High & Moderate \\
\hline Company & 10 & 11 & 12 & 13 & 14 & 15 & 16 & 17 & 18 \\
\hline$k=1$ & 0.5079 & 0.5447 & 0.3510 & 0.5593 & 0.4529 & 0.5317 & 0.1523 & 0.7109 & 0.4068 \\
\hline$k=2$ & 0.2733 & 0.2669 & 0.4224 & 0.2522 & 0.3328 & 0.3085 & 0.5387 & 0.1454 & 0.3438 \\
\hline$k=3$ & 0.2188 & 0.1884 & 0.2266 & 0.1885 & 0.2143 & 0.1598 & 0.3090 & 0.1437 & 0.2495 \\
\hline Risk class & High & High & Moderate & High & High & High & Moderate & High & High \\
\hline Company & 19 & 20 & 21 & 22 & 23 & 24 & 25 & 26 & 27 \\
\hline$k=1$ & 0.2824 & 0.6526 & 0.5162 & 0.5723 & 0.4246 & 0.3022 & 0.5347 & 0.2499 & 0.4502 \\
\hline$k=2$ & 0.5282 & 0.1799 & 0.2413 & 0.2351 & 0.3683 & 0.3799 & 0.2342 & 0.4477 & 0.3935 \\
\hline$k=3$ & 0.1893 & 0.1675 & 0.2426 & 0.1927 & 0.2071 & 0.3178 & 0.2311 & 0.3024 & 0.1563 \\
\hline Risk class & Moderate & High & High & High & High & Moderate & High & Moderate & High \\
\hline Company & 28 & 29 & 30 & 31 & 32 & 33 & 34 & 35 & 36 \\
\hline$k=1$ & 0.5209 & 0.2604 & 0.3934 & 0.5508 & 0.5528 & 0.5722 & 0.2696 & 0.6099 & 0.3181 \\
\hline$k=2$ & 0.2562 & 0.5703 & 0.4272 & 0.2380 & 0.2651 & 0.2275 & 0.5244 & 0.2596 & 0.4460 \\
\hline$k=3$ & 0.2229 & 0.1693 & 0.1794 & 0.2112 & 0.1821 & 0.2003 & 0.2060 & 0.1305 & 0.2359 \\
\hline Risk class & High & Moderate & Moderate & High & High & High & Moderate & High & Moderate \\
\hline Company & 37 & 38 & 39 & 40 & 41 & 42 & 43 & 44 & 45 \\
\hline$k=1$ & 0.3488 & 0.3204 & 0.3418 & 0.4369 & 0.2832 & 0.5299 & 0.4077 & 0.2227 & 0.2741 \\
\hline$k=2$ & 0.4693 & 0.5312 & 0.3006 & 0.3823 & 0.4145 & 0.2608 & 0.3538 & 0.3763 & 0.4340 \\
\hline$k=3$ & 0.1819 & 0.1484 & 0.3576 & 0.1807 & 0.3024 & 0.2094 & 0.2384 & 0.4009 & 0.2919 \\
\hline Risk class & Moderate & Moderate & Low & High & Moderate & High & High & Low & Moderate \\
\hline Company & 46 & 47 & 48 & 49 & 50 & 51 & 52 & 53 & 54 \\
\hline$k=1$ & 0.8050 & 0.2771 & 0.4967 & 0.4668 & 0.5269 & 0.4118 & 0.3854 & 0.4608 & 0.3822 \\
\hline$k=2$ & 0.0930 & 0.4465 & 0.3122 & 0.3020 & 0.3037 & 0.4161 & 0.3973 & 0.3813 & 0.4242 \\
\hline$k=3$ & 0.1020 & 0.2765 & 0.1910 & 0.2312 & 0.1695 & 0.1720 & 0.2173 & 0.1579 & 0.1936 \\
\hline Risk class & High & Moderate & High & High & High & Moderate & Moderate & High & Moderate \\
\hline Company & 55 & 56 & 57 & 58 & 59 & 60 & 61 & 62 & \\
\hline$k=1$ & 0.4156 & 0.6032 & 0.3293 & 0.6441 & 0.5975 & 0.2837 & 0.2042 & 0.2186 & \\
\hline$k=2$ & 0.3503 & 0.2484 & 0.4594 & 0.2387 & 0.2570 & 0.5091 & 0.4598 & 0.4919 & \\
\hline$k=3$ & 0.2341 & 0.1484 & 0.2113 & 0.1172 & 0.1455 & 0.2071 & 0.3360 & 0.2895 & \\
\hline Risk class & High & High & Moderate & High & High & Moderate & Moderate & Moderate & \\
\hline
\end{tabular}


Therefore, according to the company's operating performance, the grey cluster group is divided into three categories $(k=1,2,3)$. The grey whitenization functions $f_{j k}$ of other indicators for the three categories are: high-risk probability company $(k=1)$, the grey number is $x \in[0,0.5)$; moderate-risk probability company $(k=2)$, the grey number is $x \in[0,0.5,1)$ and low-risk probability company $(k=3)$, the grey number is $x \in[0.5,1)$.

Step 3: Through the calculation of the grey clustering coefficient $\sigma_{i k}$ for the alternative $i$ belonging to the $k$-th grey class, we can obtain the cluster coefficient matrix shown in Table 4.

Step 4: Table 4 shows that the clustering vector $\sigma_{i}$ of company 1 is $(0.596,0.276$, 0.128 ), showing whether the company's membership grade in low, medium or high-risk. The three categories are $0.596,0.276$ and 0.128 , respectively. Through the cluster coefficient $\sigma_{i k^{*}}=\max _{1 \leq k \leq n}\left\{\sigma_{i k}\right\}=0.596$, company 1 was considered to belong in the high-risk company group, and so forth. The grey classification results (see Table 4) are as follows: Low-risk probability company group:

Company 39, 44;

Moderate-risk probability company group:

Company 2, 5, 7, 9, 12, 16, 19, 24, 26, 29, 30, 34, 36-38, 41, 45, 47, 51, 52, 54, 57, 60-62;

High-risk probability company group:

Company 1, 3, 4, 6, 8, 10, 11, 13-15, 17, 18, 20-23, 25, 27, 28, 31-33, 35, 40, 42, 43, $46,48-50,53,55,56,58,59$.

\subsection{The effect of the representative indicators of performance}

By using Eqs. (13)-(16), we can calculate the weight of 14 representative indicators. The results are shown in Table 5. Table 5 shows that the weights of indicator S5 (longterm capital ratio), O3 (inventory turnover) and S4 (quick ratio) are 0.0854, 0.0768 and 0.0704, respectively. These are the most important three indicators of performance for Taiwan's listed opto-electronics companies:

Table 5. The results of grey entropy weight

\begin{tabular}{cccccccc}
\hline Indicator & DOL & $\beta$ & S2 & S3 & S4 & S5 & S8 \\
\hline Weight & 0.0696 & 0.0697 & 0.0697 & 0.0702 & 0.0704 & 0.0854 & 0.0697 \\
\hline Indicator & P4 & P5 & P6 & O1 & O3 & O5 & O6 \\
\hline Weight & 0.0698 & 0.0696 & 0.0697 & 0.0698 & 0.0768 & 0.0699 & 0.0696 \\
\hline
\end{tabular}

\subsection{Results of the VIKOR-E method for performance evaluation}

Firstly, according to Eqs (17) and (18), we can find the positive ideal solution and negative ideal solution for each representative criterion. Then the grey entropy weights of 
the 14 evaluation criteria are substituted into Eqs (19) and (20) to obtain the $S_{k}$ and $R_{k}$ values. Finally, the $Q_{k}$ value is calculated using Eq. (21) when $v$ is set to 0.5. Table 6 lists the empirical results obtained via sorting by the values of $Q$ in decreasing order.

After calculating the evaluation values of $S, R$ and $Q$ for each company, based on the two conditions mentioned earlier in section 2.4 , we determine the final ranking results for each company group. First, calculate the threshold value of acceptable advantage. In this study, the threshold values (Eq. (22)) for low, moderate and high-risk company group are $1 /(2-1)=1,1 /(25-1)=0.0417$ and $1 /(35-1)=0.0294$, respectively. By the empirical results of the moderate-risk company group (see Table 6), the $Q$ value difference between the first sorting (company 30) and second (company 52) (by descending order) is 0.1009 , which is higher than the threshold value 0.0417 , in line with the acceptable advantage of the threshold conditions. Therefore, company 30 has an acceptable advantage that is; company 30 is preferred to company 52. The $Q$ value, difference between the third sorting (company 7) and second (company 52), is 0.0191, which is less than the threshold value of 0.0417 . It means company 52 did not have an acceptable advantage. Therefore, there is no obvious gap between the operating performances of the two companies, so the ranking is the same as this result. Therefore, we accept that there is no obvious gap between the operating performances of company 52 and 7, so the company 52 is ranked second. Similarly, we can follow the conditions of section 2.4 to get the rank of moderate and high-risk groups of companies operating performance results, respectively, as follows:

Low-risk probability company group:

Company $39 \approx 44$;

Moderate-risk probability company group:

Company

$30 \succ 7 \approx 52 \succ 2 \approx 34 \approx 54 \succ 5 \approx 29 \approx 51 \approx 62 \succ 19 \approx 37 \succ 16 \approx 24 \approx 26 \approx 38 \approx 60$

$\succ 57 \succ 9 \approx 12 \succ 36 \approx 47 \succ 41 \succ 45 \succ 61$;

High-risk probability company group:

Company

$11 \approx 28 \succ 6 \approx 25 \approx 55 \approx 58 \succ 4 \approx 53 \succ 10 \approx 27 \approx 49 \succ 18 \approx 23 \succ 48 \approx 56 \succ 8 \succ 15 \approx 21$

$\approx 35 \approx 43 \succ 14 \approx 33 \approx 40 \succ 20 \approx 42 \succ 13 \approx 17 \succ 50 \approx 59 \succ 3 \approx 32 \approx 46 \succ 31 \succ 22 \succ 1$,

where $A \succ B$ indicates that $A$ is preferred to $B, A \approx B$ indicates that there is no significant difference between $A$ and $B$. The ranking results for each group are shown in Table 7.

Table 7 shows that the two companies in the low-risk company group. The 25 companies in the moderate risk company group were divided into 1-12 grades, where company 30 has the best operating performance within the group. The last three companies are company 41,45 and 61 , respectively. The 35 companies in the high risk company group were divided into 1-16 grades. Among them, company 11 and 28 has better operating performance. The three companies with the worst performance are company 
Table 6. The values of $S, R$ and $Q$ for all companies

\begin{tabular}{|c|c|c|c|c|c|c|c|c|c|c|c|}
\hline \multicolumn{4}{|c|}{ Low risk company group } & \multicolumn{4}{|c|}{ Moderate risk company group } & \multicolumn{4}{|c|}{ High risk company group } \\
\hline Company & $S_{j}$ & $R_{j}$ & $Q_{j}$ & Company & $S_{j}$ & $R_{j}$ & $Q_{j}$ & Company & $S_{j}$ & $R_{j}$ & $Q_{j}$ \\
\hline 39 & 0.4348 & 0.0854 & 0.5 & 2 & 0.3269 & 0.0842 & 0.2107 & 1 & 0.6287 & 0.0844 & 0.8891 \\
\hline \multirow[t]{34}{*}{44} & 0.5651 & 0.0768 & 0.5 & 5 & 0.4323 & 0.0854 & 0.3162 & 3 & 0.5876 & 0.0835 & 0.7454 \\
\hline & & & & 7 & 0.2765 & 0.0586 & 0.1200 & 4 & 0.5393 & 0.0742 & 0.3489 \\
\hline & & & & 9 & 0.5251 & 0.2571 & 0.6827 & 6 & 0.4851 & 0.0758 & 0.2348 \\
\hline & & & & 12 & 0.5505 & 0.2526 & 0.7006 & 8 & 0.5053 & 0.0834 & 0.5040 \\
\hline & & & & 16 & 0.5058 & 0.1272 & 0.4555 & 10 & 0.5369 & 0.0761 & 0.3933 \\
\hline & & & & 19 & 0.4197 & 0.1256 & 0.3683 & 11 & 0.5239 & 0.0672 & 0.1123 \\
\hline & & & & 24 & 0.4545 & 0.1462 & 0.4355 & 13 & 0.5859 & 0.0808 & 0.6658 \\
\hline & & & & 26 & 0.4921 & 0.1232 & 0.4357 & 14 & 0.5293 & 0.0851 & 0.6211 \\
\hline & & & & 29 & 0.3830 & 0.1065 & 0.3016 & 15 & 0.5357 & 0.0819 & 0.5497 \\
\hline & & & & 30 & 0.1750 & 0.0459 & 0.0000 & 17 & 0.6371 & 0.0764 & 0.6920 \\
\hline & & & & 34 & 0.3184 & 0.0960 & 0.2211 & 18 & 0.4919 & 0.0825 & 0.4389 \\
\hline & & & & 36 & 0.5988 & 0.2817 & 0.7946 & 20 & 0.6164 & 0.0761 & 0.6248 \\
\hline & & & & 37 & 0.4258 & 0.1354 & 0.3901 & 21 & 0.5326 & 0.0822 & 0.5495 \\
\hline & & & & 38 & 0.4542 & 0.1427 & 0.4297 & 22 & 0.5971 & 0.0854 & 0.8245 \\
\hline & & & & 41 & 0.6418 & 0.2793 & 0.8332 & 23 & 0.5038 & 0.0808 & 0.4274 \\
\hline & & & & 45 & 0.6382 & 0.3204 & 0.8955 & 25 & 0.5428 & 0.0704 & 0.2549 \\
\hline & & & & 47 & 0.6045 & 0.2702 & 0.7818 & 27 & 0.5346 & 0.0767 & 0.4030 \\
\hline & & & & 51 & 0.4115 & 0.1005 & 0.3199 & 28 & 0.4926 & 0.0696 & 0.0866 \\
\hline & & & & 52 & 0.2552 & 0.0597 & 0.1009 & 31 & 0.6100 & 0.0823 & 0.7777 \\
\hline & & & & 54 & 0.3062 & 0.0804 & 0.1841 & 32 & 0.6080 & 0.0824 & 0.7731 \\
\hline & & & & 57 & 0.4980 & 0.2274 & 0.6085 & 33 & 0.5424 & 0.0827 & 0.5921 \\
\hline & & & & 60 & 0.4228 & 0.1624 & 0.4303 & 35 & 0.5841 & 0.0768 & 0.5500 \\
\hline & & & & 61 & 0.6836 & 0.3578 & 1.0000 & 40 & 0.5293 & 0.0852 & 0.6214 \\
\hline & & & & 62 & 0.4038 & 0.1104 & 0.3284 & 42 & 0.5350 & 0.0854 & 0.6444 \\
\hline & & & & & & & & 43 & 0.5285 & 0.0829 & 0.5567 \\
\hline & & & & & & & & 46 & 0.6577 & 0.0762 & 0.7476 \\
\hline & & & & & & & & 48 & 0.5494 & 0.0772 & 0.4592 \\
\hline & & & & & & & & 49 & 0.5216 & 0.0784 & 0.4120 \\
\hline & & & & & & & & 50 & 0.5652 & 0.0842 & 0.6992 \\
\hline & & & & & & & & 53 & 0.5221 & 0.0764 & 0.3584 \\
\hline & & & & & & & & 55 & 0.5265 & 0.0718 & 0.2449 \\
\hline & & & & & & & & 56 & 0.5583 & 0.0764 & 0.4645 \\
\hline & & & & & & & & 58 & 0.4896 & 0.0755 & 0.2418 \\
\hline & & & & & & & & 59 & 0.5883 & 0.0819 & 0.7031 \\
\hline
\end{tabular}


Table 7. The ranking of the companies by $S, R$ and $Q$

\begin{tabular}{|c|c|c|c|c|c|}
\hline \multicolumn{2}{|c|}{ Low-risk company group } & \multicolumn{2}{|c|}{ Moderate-risk company group } & \multicolumn{2}{|c|}{ High-risk company group } \\
\hline Rank & Company & Rank & Company & Rank & Company \\
\hline \multirow[t]{16}{*}{1} & 39,44 & 1 & 30 & 1 & 11,28 \\
\hline & & 2 & 7,52 & 2 & $6,25,55,58$ \\
\hline & & 3 & $2,34,54$ & 3 & 4,53 \\
\hline & & 4 & $5,29,51,62$ & 4 & $10,27,49$ \\
\hline & & 5 & 19,37 & 5 & 18,23 \\
\hline & & 6 & $16,24,26,38,60$ & 6 & 48,56 \\
\hline & & 7 & 57 & 7 & 8 \\
\hline & & 8 & 9,12 & 8 & $15,21,35,43$ \\
\hline & & 9 & 36,47 & 9 & $14,33,40$ \\
\hline & & 10 & 41 & 10 & 20,42 \\
\hline & & 11 & 45 & 11 & 13,17 \\
\hline & & 12 & 61 & 12 & 50,59 \\
\hline & & & & 13 & $3,32,46$ \\
\hline & & & & 14 & 31 \\
\hline & & & & 15 & 22 \\
\hline & & & & 16 & 1 \\
\hline
\end{tabular}

31, 22 and 1. That is, among the listed opto-electronics company in Taiwan, the operating crisis probability of these three companies is the highest. The managers of these companies should improve the efficiency of resource allocation, and investors making investment decisions should avoid these three companies. In order to ensure sound investment strategy, we recommend that investors should choose the low-risk company group, or the companies with better performance in the moderate-risk company group as investment targets. By doing so, they may be able to reduce investment risk.

\section{Conclusions}

In order to verify the proposed investment decision-making process, we conducted a case study of Taiwan's 62 listed opto-electronics companies. This study utilized globalized MGRA, from 21 financial ratios, to select 12 representative financial performance indicators, together with two indicators to measure risk, and a total of 14 indicators for performance evaluation. We then divided the 62 GCA classified companies into three groups: low, moderate and high-risk company groups. Finally, the VIKOR-E method was used to solve the MCDM problem. The VIKOR-E method was also used to conduct a comprehensive evaluation of the low, moderate and high-risk company groups, respectively.

The empirical results show that "long-term capital ratio", "quick ratio" and "inventory turnover" were the three most important indicators affecting the financial performance 
of Taiwan's opto-electronics company. The "DOL" and "beta coefficient" were the two representative indicators for measuring the investment risk. The GCA results show that there are 2, 25 and 35 companies belonging to the low, moderate and high-risk probability company groups, respectively. The results of the VIKOR-E method show that in the low-risk company group, company 39 and 44 have better performance. In the moderate risk company group, company 30 has the best performance. In the high-risk probability company group, companies 11 and 28 have better performance. Companies 31,22 and 1 were the companies with the worst operating performance. Investors should avoid buying the assets of these three companies. Investors and creditors can use the proposed methods to evaluate companies' financial position and operating performance, along with other relevant information, for a more accurate judgment, or as a reference to make the best investment and credit decisions. Furthermore, this approach is applicable when investors face with situations in which investors have to make decision with limited information when multiple evaluation criteria and multiple investment targets are presented.

\section{References}

Alaghi, K. 2012. Operating leverage and systematic risk, African Journal of Business Management 6(3): 1095-1099. http://dx.doi.org/10.5897/AJBM11.2266

Bowman, R. G. 1979. The theoretical relationship between systematic risk and financial (accounting) variables, Journal of Finance 34(3): 617-630.

http://dx.doi.org/10.1111/j.1540-6261.1979.tb02129.x

Deng, J. L. 1987. Basic methodology of grey system. Wuhan: Publishing House of Huazhong University of Science \& Technology.

Feng, C. M.; Wang, R. T. 2000. Performance evaluation for airlines including the consideration of financial ratios, Journal of Air Transport Management 6(3): 133-142.

http://dx.doi.org/10.1016/S0969-6997(00)00003-X

Golmohammadi, D.; Mellat-Parast, M. 2012. Developing a grey-based decision-making model for supplier selection, International Journal of Production Economics 137(2): 191-200.

http://dx.doi.org/10.1016/j.ijpe.2012.01.025

Halkos, G. E.; Tzeremes, N. G. 2012. Industry performance evaluation with the use of financial ratios: an application of bootstrapped DEA, Expert Systems with Applications 39(5): 5872-5880. http://dx.doi.org/10.1016/j.eswa.2011.11.080

Hallerbach, W.; Spronk, J. 2002. A multidimensional framework for financial-economic decisions, Journal of Multi-Criteria Decision Analysis 11(3): 111-124.

http://dx.doi.org/10.1002/mcda.324

Hamada, R. S. 1972. The effect of the firm's capital structure on the systematic risk of common stocks, Journal of Finance 27(2): 435-452. http://dx.doi.org/10.2307/2978486

Han, Z.; Liu, P. 2011. A fuzzy multi-attribute decision-making method under risk with unknown attribute weights, Technological and Economic Development of Economy 17(2): 246-258. http://dx.doi.org/10.3846/20294913.2011.580575

Hsu, K. T. 2011. Using a back propagation network combined with grey clustering to forecast policyholder decision to purchase investment-inked insurance, Expert Systems with Applications 38(6): 6736-6747. http://dx.doi.org/10.1016/j.eswa.2010.11.060 
Hsu, L. C.; Ou, S. L.; Yang, C. C.; Ou, Y. C. 2012. How to choose mutual funds that perform well? Evidence from Taiwan, International Journal of Economics and Finance 4(1): 247-259. http://dx.doi.org/10.5539/ijef.v4n1p247

Ilangkumaran, M.; Kumanan, S. 2012. Application of hybrid VIKOR model in selection of maintenance strategy, International Journal of Information Systems and Supply Chain Management 5(2): 59-81. http://dx.doi.org/10.4018/IJISSCM.2012040104

Liu, K.; Shen, X.; Tan, Z.; Guo, W. 2012. Grey clustering analysis method for overseas energy project investment risk decision, Systems Engineering Procedia 3: 55-62.

http://dx.doi.org/10.1016/j.sepro.2011.11.008

Liu, P.; Wang, M. 2011. An extended VIKOR method for multiple attribute group decision making based on generalized interval-valued trapezoidal fuzzy numbers, Scientific Research and Essays 6(4): 766-776 [online], [cited 21 Mar 2012]. Available from Internet:

http://www.academicjournals.org/SRE

Mohaghar, A.; Fathi, M. R.; Zarchi, M. K.; Omidian, A. 2012. A combined VIKOR-fuzzy AHP approach to marketing strategy selection, Business Management and Strategy 3(1): 13-27. http://dx.doi.org/10.5296/bms.v3i1.957

Olson, D. 2004. Comparison of weights in TOPSIS models, Mathematical and Computer Modelling 40(7-8): 721-727. http://dx.doi.org/10.1016/j.mcm.2004.10.003

Opricovic, S. 1998. Multicriteria optimization of civil engineering systems. $\mathrm{PhD}$ thesis. Faculty of Civil Engineering, Belgrade.

Opricovic, S.; Tzeng, G. H. 2007. Extended VIKOR method in comparison with outranking methods, European Journal of Operational Research 178(2): 514-529.

http://dx.doi.org/10.1016/j.ejor.2006.01.020

Pramanik, S.; Mukhopadhyaya, D. 2011. Grey relational analysis based intuitionistic fuzzy multicriteria group decision-making approach for teacher selection in higher education, International Journal of Computer Applications 34(10): 21-29. http://dx.doi.org/10.5120/4138-5985

Prokopczuk, M.; Rachev, S. T.; Schindlmayr, G.; Trueck, S. 2007. Quantifying risk in the electricity business: a RAROC-based approach, Energy Economics 29(5): 1033-1049.

http://dx.doi.org/10.1016/j.eneco.2006.08.006

Shih, H. S.; Shyur, H. J.; Lee, E. S. 2007. An extension of TOPSIS for group decision making, Mathematical and Computer Modelling 45(7): 801-813.

http://dx.doi.org/10.1016/j.mcm.2006.03.023

Stankevičienè, J.; Mencaitė, E. 2012. The evaluation of bank performance using a multicriteria decision making model: a case study on Lithuanian commercial banks, Technological and Economic Development of Economy 18(1): 189-205.

http://dx.doi.org/10.3846/20294913.2012.668373

Wang, Y. J. 2009. Combining grey relation analysis with FMCGDM to evaluate financial performance of Taiwan container lines, Expert Systems with Applications 36(2): 2424-2432.

http://dx.doi.org/10.1016/j.eswa.2007.12.027

Wu, H. Y.; Chen, J. K.; Chen, I.; Zhuo, H. H. 2012. Ranking universities based on performance evaluation by a hybrid MCDM model, Measurement 45(5): 856-880.

http://dx.doi.org/10.1016/j.measurement.2012.02.009

Yalçin, N.; Bayraktaroğlu, A.; Kahraman, C. 2012. Application of fuzzy multi-criteria decision making methods for financial performance evaluation of Turkish manufacturing industries, Expert Systems with Applications 39(1): 350-364. http://dx.doi.org/10.1016/j.eswa.2011.07.024

You, M.; Wen, K. 2005. Applying Matlab to create a grey entropy toolbox for use in teacher appraisals, World Transactions on Engineering and Technology Education 4(2): 281-284 [online], [cited 21 Mar 2012]. Available from Internet: http:/www.wiete.com.au/journals/WTE\&TE/ Pages/Vol.4,\%20No.2\%20(2005)/26-Wen30.pdf 
Zavadskas, E. K.; Kaklauskas, A.; Turskis, Z.; Tamošaitienė, J. 2009. Multi-attribute decisionmaking model by applying grey numbers, Informatica 20(2): 305-320 [online], [cited 21 Mar 2012]. Available from Internet: http://www.mii.lt/Informatica/pdf/info750.pdf

Zhang, J. F.; Wu, Z. J.; Feng, P. F.; Yu, D. W. 2011. Evaluation systems and methods of enterprise informatization and its application, Expert Systems with Applications 38(7): 8938-8948.

http://dx.doi.org/10.1016/j.eswa.2011.01.111

Li-Chang HSU is a Professor of economics at Ling Tung University, in Taiwan. His research areas are decision-making theory and practice, grey system theory and technology management. His articles are published by Technological and Economic Development of Economy, Journal of Business Economics and Management, British Journal of Management, Technological Forecasting and Social Change, Expert Systems with Application, Service Business, Journal of Electronic Commerce Research and others. 